Deteksi Fraudulent Financial Statement: Pengujian Dengan Analisis Proksi Fraud Triangle

\title{
DETEKSI FRAUDULENT FINANCIAL STATEMENT: PENGUJIAN DENGAN ANALISIS PROKSI FRAUD TRIANGLE
}

\author{
Made Irma Lestari \\ Sekolah Tinggi Ilmu Ekonomi Wiyatamandala \\ made.irma@wym.ac.id \\ Vosby Florensi \\ Universitas Gadjah Mada \\ vosby95@gmail.com
}

\begin{abstract}
This study is an empirical study that aims to determine the effect of the fraud triangle proxies on the potential on fraudulent financial statements of go-public companies on the Indonesia Stock Exchange. This study uses 22 companies that are members of the LQ-45 company for the 20162020 period. The test results with multiple linear regression showed that simultaneously financial targets, financial stability, external pressure, nature of industry, and change in auditors had a significant positive effect on fraudulent financial statements. Partially, the Pressure Factor with the Financial Stability proxy has a significant positive influence on the potential for financial statement fraud. However, the results of the simultaneous test of proxies for pressure factors, namely financial target, financial stability, and external pressure, did not have a significant effect. The partial test results on each variable state that the other hypotheses, namely financial targets, external pressure, nature of industry, and change in auditors, do not have a significant positive effect on potential fraud in financial statements.
\end{abstract}

Keywords: Fraudulent Financial Statement, Pressure, Opportunity, Rationalization.

\begin{abstract}
ABSTRAK
Penelitian ini merupakan penelitian empiris yang bertujuan mengetahui pengaruh proksi-proksi fraud triangle terhadap potensi adanya tindakan fraud pada laporan keuangan pada perusahaan go-publik di Bursa Efek Indonesia. Penelitian ini menggunakan 22 perusahaan yang tergabung dalam perusahaan LQ-45 untuk periode 2016-2020. Hasil pengujian dengan regresi linier berganda menghasilkan bahwa secara simultan financial target, financial stability, external pressure, nature of industry, dan change in auditor memiliki pengaruh signifikan positif terhadap fraud pada laporan keuangan. Secara parsial, Pressure Factor dengan proksi Financial Stability memiliki pengaruh signifikan positif pada adanya potensi fraud laporan keuangan. Namun, hasil uji secara simultan terhadap proksi-proksi faktor pressure yaitu financial target, financial stability, dan external pressure tidak memiliki pengaruh signifikan. Hasil pengujian secara parsial atas masing-masing variabel menyatakan bahwa hipotesis lainnya yaitu financial target, external pressure, nature of industry, dan change in auditor tidak memiliki pengaruh signifikan positif terhadap potensi fraud pada laporan keuangan.
\end{abstract}

Kata kunci: Kecurangan Laporan Keuangan, Tekanan, Kesempatan, Rasionalisasi. 


\section{PENDAHULUAN}

Laporan keuangan ialah sarana komunikasi antara pengguna dengan entitas penerbit. Untuk dapat memberikan informasi keuangan yang tepat kepada publik, laporan keuangan harus bebas dari fraud. Fraud atau kecurangan yang disengaja terkait transaksi keuangan dalam suatu entitas menjadi urgensi untuk dapat diambil tindakan preventif dan korektif sehingga fraud itu sendiri tidak terulang. Untuk itu, peneliti bertujuan memperkaya literasi terkait proksi dan indikator penilaian fraud laporan keuangan entitas. Banyak penelitian yang telah dilakukan terkait ini. Namun, penelitian sejenis untuk tahun 2020 (selama masa pandemi Covid-19) belum pernah dilakukan. Peneliti merasa penting untuk melakukan penelitian ini disebabkan perubahan kinerja keuangan selama pandemi Covid-19 mungkin akan memberikan hasil yang signifikan berbeda dari penelitian sebelumnya. Penelitian Ananda Putra N.A.H. dan Gideon Setyo B.(2019)memberikan hasil bahwa financial target, external pressure, nature of industry, dan change in auditor tidak bisa digunakan sebagai indikator dalam menilai potensi terjadinya fraud di perusahaan. Penelitan yang dilakukan Merissa Yesiarini dan Isti Rahayu (2017) menghasilkan bahwa financial stability tidak bisa digunakan sebagai indikator dalam menilai fraud di perusahaan. Peneliti menggunakan sampel perusahaan yang termasuk ke dalam indeks LQ-45 di Bursa Efek Indonesia (BEI). Masyarakat akan cenderung berpikir bahwa dengan kualitas saham dan tingkat likuiditas yang baik, laporan keuangan yang dihasilkan oleh perusahaan yang termasuk LQ-45 telah terbebas dari kecurangan laporan keuangan, padahal hal tersebut tidak dapat menjamin laporan keuangan akan bebas dari fraud (Noble, 2019). Peneliti memperpanjang tahun pengamatan menjadi 5 (lima) tahun terakhir dengan harapan hasil penelitian ini memberikan hasil yang lebih aktual dan akurat dibandingkan dengan penelitian-penelitian terdahulu. Berdasarkan latar belakang dan perbedaan hasil dari penelitian-penelitian sebelumnya tersebut, peneliti merasa penting untuk melakukan analisis fraud dengan proksi fraud triangle (pressure, opportunity, dan rationalization) dalam mendeteksi fraud laporan keuangan. Peneliti berharap dapat menemukan pengaruh positif pada financial target, financial stability, external pressure, nature of industry, dan changes in auditor. Peneliti menambah dua (2) variabel untuk 
memperkuat analisis faktor tekanan (pressure) pada penelitian ini, sehingga terdapat 3 (tiga) proksi penilaian faktor

\section{TELAAH LITERATUR}

Teori fraud triangle menurut teori yang diajukan oleh Cressey pada tahun 1953 (dalam (Abdullahi \& Noorhayati, 2015)) terdiri atas tiga penyebab kecurangan yaitu tekanan, peluang, dan rasionalisasi. Peluang membuka pintu untuk melakukan kecurangan, sedangkan tekanan dan rasionalisasi menarik orang tersebut untuk masuk dan melewatinya (Wolfe \& Hermanson, 2004).

\section{Fraud}

Association of Certified Frand Examiners (ACFE) dalam Kennedy dan Siregar (2017), mendefinisikan fraud sebagai suatu tindakan pelanggaran hukum yang disengaja untuk tujuan tertentu (memanipulasi atau memberikan informasi yang tidak benar kepada pihak lain) oleh pihak-pihak di dalam maupun di luar organisasi untuk memperoleh keuntungan personal maupun kelompok, baik secara langsung maupun tidak langsung menyebabkan kerugikan bagi pihak lain. Albrecht et al. (2011) pressure yaitu financial target, financial stability, dan external pressure.

menjelaskan fraud sebagai suatu penyajian tentang poin material yang keliru yang dilakukan secara sengaja dan ceroboh, dipercayai dilakukan oleh korban yang menyebabkan kerugian korban itu sendiri.

\section{Fraud Laporan Keuangan}

Fraud laporan keuangan ialah tindakan disengaja untuk menyajikan informasi keuangan yang salah yang menyebabkan kesalahan pengambilan keputusan keuangan baik oleh investor, kreditor, dan pihak berkepentingan lainnya. Menurut ACFE (Rezaee, 2002), fraud laporan keuangan dapat dilakukan secara sengaja dengan membuat salah saji, atau mengeliminasi informasi yang bersifat material, atau memanipulasi data akuntansi. Fraud laporan keuangan, menurut Albrecht (2011), adalah: (1) anomali akuntansi, (2) internal yang lemah kontrol, (3) anomali analisis, (4) berlebihan gaya hidup, (5) perilaku yang tidak biasa, dan (6) keluhan. Fraud laporan keuangan bisa dilakukan dengan penyajian lebih (overstating) atas aset, penjualan, dan laba, atau penyajian lebih kecil (understating) atas utang, biaya, dan 
kerugian. Menurut Wilopo (2014), fraud laporan keuangan terjadi karena didasarkan pada tujuan untuk memikat perhatian investor, menghilangkkan pandangan negatif di pasar, selain itu dalam hal akuisisi, untuk memperoleh harga jual yang lebih tinggi, dan agar tujuan dan sasaran perusahaan tercapai, terakhir memperoleh bonus yang berkaitan dengan kinerja.

Financial Target as Pressure Factor pada Fraud Laporan Keuangan

Tekanan (pressure) merupakan salah satu faktor penyebab dalam fraud triangle. Berdasarkan SAS no. 99, terdapat empat (4) kondisi umum yang mampu menjelaskan tekanan yaitu financial stability, financial targets, personal financial needs, dan external pressure. Dalam penelitian kali ini, peneliti menggunakan tiga dari empat kondisi umum tersebut, yaitu financial stability, financial targets, dan external pressure. Sebagai agen dalam prinsip keagenan (agency theory), manajemen merasakan bahwa financial target merupakan standar pencapaian keuangan yang diatur oleh pemilik (stockholder). Manajemen memiliki tanggung jawab untuk dapat mencapai target standar tersebut sehingga mendapatkan penilaian kinerja yang baik dan mendapatkan reward berupa bonus. Hal ini justru menjadi penyebab conflict of interest, di mana pemilik menginginkan kinerja keuangan yang baik untuk return optimal, di sisi lain, manajemen ingin mendapatkan bonus. Conflict of interest ini memicu manajemen melakukan tindakan apapun untuk mendapatkan bonus sekaligus mencapai target yang disyaratkan pemilik, salah satunya melakukan fraud laporan keuangan. Menurut Manurung \& Hardika (2015), financial targets yang disyaratkan oleh pemilik merupakan tolok ukur bagi pemilik untuk menilai kinerja keuangan manajemen dilihat dari tingkat profitabilitas perusahaan. Maka rasio profitabilitas dengan Return on Assets (ROA) digunakan sebagai indikator financial targets. ROA adalah rasio tingkat pengembalian atas aset dalam hal memperoleh pengembalian tersebut, juga mengukur seberapa besar kemampuan perusahaan dalam memanfaatkan asetasetnya untuk memperoleh profit (Noble, 2019). Sebagai ukuran profitabilitas yang lazim digunakan, manajemen akan selalu mencoba untuk menghasilkan ROA yang tinggi agar kinerja keuangan perusahaan dipandang baik bagi pemilik ataupun calon pemilik (share holders).

Berdasarkan pemaparan di atas, hipotesis yang diajukan ialah: 
$\mathbf{H}_{\mathbf{1} \mathbf{a}}$ : Pressure Factor dengan proksi Financial Target berpengaruh positif pada adanya potensi fraud laporan keuangan

\section{Financial Stability as Pressure Factor pada Fraud Laporan Keuangan}

Fraud laporan keuangan dapat disebabkan oleh faktor tekanan dari stabilitas keuangan entitas. Kondisi keuangan perusahaan yang tidak stabil dapat memicu terjadinya fraud karena stabilitas keuangan sebagai tolak ukur kinerja perusahaan melalui pertumbuhan keuangan yang stabil. Kondisi keuangan perusahaan dianggap stabil apabila dapat memenuhi kebutuhan saat ini, masa depan, serta kebutuhan yang terdesak. Maka dari itu, manajer akan melakukan berbagai langkah agar perusahaan dalam kondisi stabil (Bawekes, 2018). Kurnia \& Anis (2017) membuktikan bahwa stabilitas keuangan dengan perubahan total aset sebagai proksi dapat mempengaruhi terjadinya kecurangan dalam laporan keuangan. Semakin tinggi rasio perubahan aset, semakin besar kemungkinan terjadinya fraud laporan keuangan melalui manipulasi laba. Dengan kata lain, semakin stabil aset, semakin kecil kemungkinan untuk melakukan fraud keuangan.

Maka peneliti mengajukan hipotesis sebagai berikut:
$\mathbf{H}_{\mathbf{1 b}}$ : Pressure Factor dengan proksi Financial Stability berpengaruh positif pada adanya potensi fraud laporan keuangan

\section{External Pressure as Pressure Factor pada} Fraud Laporan Keuangan

Faktor tekanan dari eksternal juga dapat menjadi penyebab fraud laporan keuangan. Manajemen perusahaan kadang kala merasakan tekanan dari pihak eksternal untuk memenuhi hal-hal yang menjadi kewajiban (Skousen, 2009). Adanya tekanan eksternal dapat memicu manajemen untuk melakukan kecurangan karena adanya kebutuhan untuk mengembalikan modal yang diperolehnya. Suatu perusahaan dapat mengembalikan utangnya jika kegiatan operasionalnya berjalan terus menerus dan tidak mengalami kerugian (Ravisankar, 2011). Jika rasio leverage perusahaan tinggi, mereka memiliki jumlah utang yang besar dan risiko kredit yang tinggi. Oleh karena itu, fraud digunakan sebagai solusi dengan memanipulasi keuntungan yang dihasilkan (Bawekes, 2018). Kurnia dan Anis (2017), membuktikan bahwa tekanan eksternal dari kreditur dengan proksi tingkat leverage mempengaruhi terjadinya kecurangan dalam laporan keuangan. Manajer termotivasi untuk meningkatkan laba untuk memberikan 
kesan bahwa kinerja perusahaan baik dan mampu membayar utangnya.

Maka, peneliti mengajukan hipotesis sebagai berikut:

$\mathbf{H}_{\mathbf{1}}$ : Pressure Factor dengan proksi External Pressure berpengaruh positif pada adanya potensi fraud laporan keuangan

\section{Nature of Industry as Opportunity Factor} pada fraud Laporan Keuangan

Peluang ialah salah satu penyebab terjadinya kecurangan. Lemahnya pengendalian dan pengawasan internal perusahaan mengakibatkan manajemen selaku agen memiliki peluang untuk melakukan kecurangan. Terdapat tiga kondisi yang menggambarkan peluang sesuai SAS No. 99 yaitu sifat industri, pemantauan yang tidak efektif, dan struktur organisasi. Di sini peneliti menggunakan nature of indutry sebagai proksi opportunity praktik fraud laporan keuangan. Sifat industri (nature of industry) ialah kondisi ideal suatu perusahaan dalam industri. Sifat industri atau perusahaan adalah sifat perusahaan. Adanya perkiraan piutang tidak tertagih atau adanya penganggaran, diperkirakan atau tidak diperhitungkan dengan tepat (Bawekes, 2018). Penilaian piutang dapat terjadi secara subjektif dan nilai estimasian terkait dengan penentuan tidak tertagihnya piutang. Pada estimasian dan subjektivitas tersebut terdapat potensi manajemen menggunakan akun piutang sebagai alat untuk memanipulasi laporan keuangan. Dalam hal itu, para pelaku dapat menggunakannya untuk melakukan fraud.

Bastomi (2018), membuktikan bahwa sifat industri dapat mempengaruhi terjadinya kecurangan dalam laporan keuangan karena penilaian subjektif dalam penilaian dan penentuan piutang tak tertagih. Berdasarkan pemaparan tersebut, peneliti mengajukan hipotesis sebagai berikut:

$\mathbf{H}_{2}$ : Opportunity Factor dengan proksi Nature of Industry berpengaruh positif pada adanya potensi fraud laporan keuangan

\section{Change in Auditor as Rationalization} Factor pada Fraud Laporan Keuangan

Saat berganti auditor, perusahaan membutuhkan penyesuaian atau masa transisi bagi auditor dan perusahaan. Pada saat pergantian auditor, perusahaan memiliki alasan dengan merasionalkan untuk melakukan fraud. Manajemen perusahaan dapat melakukannya dengan memanfaatkan ketidakhadiran pengawas atau pengendalian dari auditor sehingga dapat terjadi kesalahan baik yang disengaja maupun tidak disengaja (Bawekes, 2018). Skousen et al (2009), 
menyatakan bahwa dalam dua tahun awal jasa audit dilakukan oleh auditor banyak kecurangan keuangan yang terjadi. Bawekes et al (2018), membuktikan bahwa perubahaan auditor dapat mempengaruhi terjadinya fraud dalam laporan keuangan. Ketika terjadi pergantian auditor, perusahaan berada dalam masa transisi dan masa stres dimana manajemen dapat merasionalisasi terjadinya kecurangan (Skousen, 2009).

Berdasarkan pemaparan tersebut, hipotesis yang diajukan ialah:

$\mathbf{H}_{3}$ : Rationalization Factor dengan proksi Change in Auditor berpengaruh positif pada adanya potensi fraud laporan keuangan

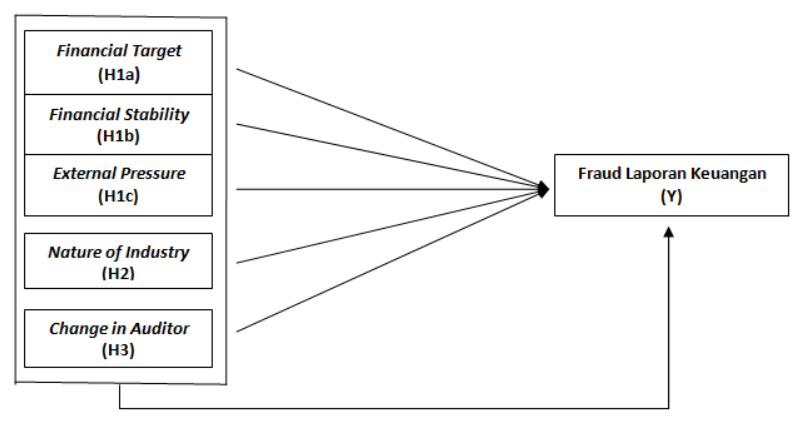

Gambar 1. Rerangka Hipotesis

\section{METODOLOGI PENELITIAN}

\section{Sampel dan Teknik Sampel}

Teknik proportional random sampling digunakan dalam penelitian ini dengan perusahaan LQ45 sebagai sampel. Pemilihan sampel disyaratkan untuk perusahaan yang secara konsisten masuk dalam kategori LQ45 pada 2016 sampai dengan 2020, tidak termasuk bank dan perusahaan finansial. Perusahaan LQ45 mewakili berbagai sektor yang mana masing-masing sektor terdiri dari beberapa perusahaan.

\section{Variabel Terikat}

Kecurangan pada laporan keuangan diukur dengan menggunakan model Fraud Score (F-Score) yang dikembangkan oleh Dechow, Ge, Larson, \& Sloan (2011), dan Kurnia \& Anis (2017). Model F-Score memiliki dua komponen variabel, yaitu kualitas akrual dan kinerja keuangan. Berikut adalah perhitungan F-Score: 
Jurnal Bina Akuntansi, Januari 2022, Vol.9, No.1, Hal. 107 - 125

$$
\text { F score }=\text { Accrual Quality }+ \text { Financial Performance }
$$

Accrual Quality dihitung menggunakan accrual (FIN), dan komponen aset akrual. rumus RSST Accural. Richardson (2005) Model perhitungannya adalah sebagai menggunakan working capital (WC), non berikut: operating capital (NCO), dan financial

$$
\text { RSST Accrual }=\frac{(\Delta W C+\Delta N C O+\Delta F I N}{\text { AverageTotalAssets }}
$$

Keterangan:

$\mathrm{WC}=($ Aset Lancar - Kas - Investasi Jangka Pendek $)-($ Utang Lancar - Pinjaman Jangka Pendek)

$\mathrm{NCO}=($ Aset Total - Aset lancar - Investasi $)-($ Utang Total - Utang Jangka Pendek - Pinjaman Jangka Panjang)

FIN $=($ Investasi jangka Pendek + Investasi Jangka Panjang $)-($ Pinjaman Jangka Panjang + Pinjaman Jangka Pendek)

$$
\text { Average total assets }=(\text { Total Aset Awal }+ \text { Total Aset Akhir }) / 2
$$

Adapun perhitungan untuk Financial Performance menurut Skousen et.al (2009) adalah sebagai berikut:

Financial Performance $=$ Perubahan Puitang + Perubahan Pada Persediaan + Perubahaan Pada Penjualan

$$
\text { Kas + Perubahan Pada earnings }
$$

Di mana:

$$
\begin{gathered}
\text { Perubahan pada piutang }=\frac{\Delta \text { Piutang }}{\text { Rata }- \text { rata Total asel }} \\
\text { Perubahaan pada persediaan }=\frac{\Delta \text { Sediaan }}{\text { rata }- \text { rata total asel }} \\
\text { Perubahaan pada penjualan kas }= \\
\left(\frac{\Delta \text { Penjualan }}{\text { pejualan }(\mathrm{t})}\right)-\left(\frac{\Delta \text { receivables }}{\text { recevables }(\mathrm{t})}\right) \\
\text { Perubahaan pada earnings }=
\end{gathered}
$$




$$
\left(\frac{\operatorname{Profit}(\mathrm{t})}{\text { Rata }- \text { rata total aset }(\mathrm{t})}\right)-\left(\frac{\operatorname{Profit}(\mathrm{t}-1)}{\text { rata }- \text { rata total aset }(\mathrm{t}-1)}\right)
$$

Variabel Bebas

Financial Target $\left(\mathrm{X}_{1 \mathrm{a}}\right)$

Dalam penelitian ini, financial target merupakan salah satu proksi faktor tekanan (pressure) dalam fraud triangle yang digunakan. Financial target diproyeksikan dalam tingkat pengembalian atas aset (ROA) dengan rumus sebagai berikut:

ROA = Earnings aftar tax / total assets

Financial Stability $\left(\mathrm{X}_{1 \mathrm{~b}}\right)$

Financial stability merupakan salah satu proksi faktor tekanan (pressure) dalam fraud triangle yang digunakan dalam penelitian ini. Financial stability diproyeksikan dalam proksi perubahan aset (achange) dengan rumus:

$$
A C H A N G E=\left(\text { total asset }_{t}-\text { total asset }_{t-1}\right) / \text { total asset }_{t}
$$

External Pressure $\left(\mathrm{X}_{1 \mathrm{c}}\right)$

External pressure merupakan salah satu proksi faktor tekanan (pressure) dalam fraud triangle yang digunakan dalam penelitian ini. External pressure diproyeksikan dalam berapa tingkat leverage yang digunakan, dengan rumus sebagai berikut:

$$
\text { Leverage }=\text { debt/total equity }
$$

Nature of Industry $\left(\mathrm{X}_{2}\right)$

Nature of Industry merupakan proksi untuk faktor kesempatan (opportunity) dalam fraud triangle yang digunakan dalam penelitian ini. Nature of Industry diproyeksikan dalam rasio piutang, dengan rumus sebagai berikut:

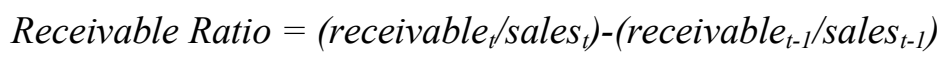


Change in Auditor $\left(\mathrm{X}_{3}\right)$

Variabel ini merupakan varibel dummy yang mana pemberian skor 1 untuk perusahaan dan periode yang melakukan penggantian auditor dari periode sebelumnya, sedangkan skor 0 apabila tidak ada penggantian.

\section{HASIL DAN ANALISIS}

Pada metode analisa yang digunakan oleh penulis adalah dengan menggunakan teknik analisis regresi berganda yang mana dengan pengolahannnya dengan menggunakan

$$
F \text { Score }=\alpha+\beta_{1 a} X 1 a+\beta_{1 b} X 1 b+\beta_{1 c} X 1 c+\beta_{2} X 2+\beta_{3} X 3+e
$$

Keterangan:

F score $=$ Fraud Pada Laporan Keuangan

$\alpha=$ konstanta

$\beta_{1 a, 1 b, 1 c, 2,3}=$ koefisien regresi

$\mathrm{X}_{1 \mathrm{a}}=\mathrm{ROA}$

$\mathrm{X}_{1 \mathrm{~b}}=$ Achange

$\mathrm{X}_{1 \mathrm{c}}=$ Leverage

$\mathrm{X}_{2}=$ Receivable Ratio

$\mathrm{X}_{3}=$ Change in Auditor

$\mathrm{e}=$ error

\section{HASIL DAN PEMBAHASAN}

Sampel yang digunakan berjumlah 110 data dimana terdiri atas perusahaan-perusahaan yang terdaftar di LQ45 dari 2016 sampai 2020 tidak termasuk bank dan perusahaan finansial. Data yang digunakan dalam penelitian dikumpulkan dari laporan keuangan dan laporan tahunan perusahaan. Data tersebut dapat diperoleh dari website bantuan SPSS versi 20 sehingga demikian model regresi berganda yang penulis rumuskan adalah sebagai berikut. 
Tabel 1 Statistik Deskriptif

\begin{tabular}{|l|r|r|r|r|r|}
\hline & $\mathrm{N}$ & \multicolumn{1}{|c|}{ Minimum } & Maximum & Mean & $\begin{array}{l}\text { Standar } \\
\text { Deviation }\end{array}$ \\
\hline ROA & 110 & -.0572238 & .4666013 & .0888521 & .09295974 \\
\hline Achange & 110 & - & .6263158 & .0760200 & .11958617 \\
\hline Leverage & 110 & .000000 & 3.313463 & .8226995 & .92269102 \\
\hline $\begin{array}{l}\text { Receivable } \\
\text { Ratio }\end{array}$ & 110 & -.1864184 & .4801245 & .0047073 & .07778623 \\
\hline $\begin{array}{l}\text { Change of } \\
\text { Auditor }\end{array}$ & 110 & .0 & 1.0 & .127 & .3348 \\
\hline F Score & 110 & -.789521 & 1.217672 & .0762814 & .35309530 \\
\hline
\end{tabular}

Sumber: Data diolah, 2021

Berdasarkan tabel statistik deskriptif di atas, jumlah data yang digunakan ialah 110 data yang terdiri atas perusahaan yang terdaftar di LQ 45 dalam rentang waktu 5 tahun (2016-2020). Variabel independen ROA memiliki rata-rata sebesar 0.08 persen dengan standar deviasi sebesar 0.09 persen.Ini menunjukkan bahwa rata-rata keuntungan yang didapatkan oleh perusahaan ialah sebesar 8 persen. Financial stability yang diproksikan dengan perubahan asset memiliki rata-rata sebesar 0.07. Ini berarti bahwa sekitar 7 persen dari total asset mengalami perubahaan dari tahun sebelumnya. Adapun external pressure yang diproksikan dengan leverage menunjukkan rata-rata sebesar 0.822 . Ini berarti bahwa rata-rata utang perusahaan ialah sebesar 82.2 persen. Variabel independen selanjutnya ialah receivable ratio memiliki rata-rata sebesar 0.004. Hal ini menunjukkan bahwa rata-rata rasio pengumpulan piutang ialah sebesar 0.4 persen. Perubahaan auditor menunjukkan nilai rata-rata sebesar 0.12 . Ini berarti bahwa terdapat 12.7 persen perusahaan yang melakukan pergantian auditor selama 5 tahun. Terakhir, untuk variabel independen dengan proksi F-Score, memiliki rata-rata sebesar 0.076 .

\section{Uji Asumsi Klasik}

Sebelum dilakukan pengujian regresi berganda, dilakukan uji asumsi klasik terlebih dahulu untuk melihat kelayakan model. Uji asumsi klasik yang digunakan ialah uji Heteroskedastisitas menggunakan Uji Glejser dan pengujian Multikolinearitas menggunakan Uji Matriks Korelasi antar Variabel. 
Tabel 2 Uji Heteroskedastisitas menggunakan Uji Glejser

\begin{tabular}{|l|r|r|c|}
\hline \multicolumn{1}{|c|}{ Model } & Koefisien & \multicolumn{1}{c|}{$\mathrm{T}$} & Sig \\
\hline Konstanta & .230 & 6.805 & .000 \\
\hline ROA $\left(\mathrm{X}_{1 \mathrm{a}}\right)$ & .192 & .897 & .372 \\
\hline Achange $\left(\mathrm{X}_{1 \mathrm{~b}}\right)$ & .201 & 1.157 & .250 \\
\hline Leverage $\left(\mathrm{X}_{1 \mathrm{c}}\right)$ & -.023 & -1.016 & .312 \\
\hline Receivable Ratio $\left(\mathrm{X}_{2}\right)$ & .190 & .713 & .477 \\
\hline $\begin{array}{l}\text { Change of Auditor } \\
\left(\mathrm{X}_{3}\right)\end{array}$ & -.088 & -1.391 & .167 \\
\hline \multicolumn{4}{|c|}{ Dependent Variable: Abs_RES } \\
\hline
\end{tabular}

Sumber: Data diolah, 2021

Berdasarkantabel Uji Heteroskedastisitas, nilai signifikansi dari masing-masing variabel independen di atas ialah 0.05 . Ini menunjukkan bahwa data tidak mengandung heteroskedastisitas. Uji asumsi klasik selanjutnya ialah uji multikolinearitas. Uji multikolinearitas digunakan untuk melihat hubungan antar variabel independen. Berdasarkan tabel di bawah ini, data tidak mengandung multikolinearitas dikarenakan nilai korelasi antar variabel tidak melebihi 0.8 .

Tabel 3 Uji Multikolinearitas menggunakan Uji Matriks Korelasi

\begin{tabular}{|l|r|r|r|r|r|r|}
\hline & \multicolumn{1}{|c|}{ ROA } & \multicolumn{1}{|c|}{ A-change } & Leverage & \multicolumn{1}{c|}{ RR } & CiA & F Score \\
\hline ROA & 1 & & & & & \\
\hline Achange & -0.00044 & 1 & & & & \\
\hline Leverage & 0.040327 & 0.249704 & 1 & & & \\
\hline $\begin{array}{l}\text { Receivable } \\
\text { Ratio }\end{array}$ & -0.06451 & 0.204678 & 0.113447 & 1 & & \\
\hline $\begin{array}{l}\text { Change of } \\
\text { Auditor }\end{array}$ & -0.13899 & 0.210327 & 0.216918 & 0.2349 & 1 & \\
\hline F Score & 0.033287 & 0.08282 & -0.07038 & - & - & \\
& & & & 0.4264 & 0.095 & \\
& & & & & & \\
& & & & & & \\
\hline
\end{tabular}

Sumber: Data diolah, 2021

\section{Uji Regresi Berganda}

Pengujian Regresi Berganda digunakan untuk melihat pengaruh positif pada financial target, financial stability, external pressure, nature of industry, dan changes in auditor dalam mendeteksi fraud laporan keuangan. Hasil uji regresi berganda dapat dilihat pada tabel di bawah ini. 
Tabel 4 Uji Regresi Berganda menggunakan Uji F

\begin{tabular}{|l|l|}
\hline & Nilai \\
\hline$R$ square & 0.216 \\
\hline Adjusted $R$ square & 0.178 \\
\hline F Statistik & 5.736 \\
\hline F signifikansi & 0.000 \\
\hline
\end{tabular}

Sumber: Data diolah, 2021

Berdasarkan tabel di atas, nilai dari $R$ square ialah sebesar 0.216. Ini berarti variabel independen mampu menjelaskan variabel dependen sebesar 21.6 persen, sedangkan sisanya dijelaskan oleh variabel lain. Untuk nilai adjusted $R$ square ialah sebesar 17.8 persen. Nilai untuk F statistik ialah sebesar 5.736 dengan signifikansi sebesar 0.000.Hal ini menunjukkan bahwa financial target, financial stability, external pressure, nature of industry, dan changes in auditor secara simultan berpengaruh signifikan terhadap fraud laporan keuangan.

Pressure Factor pada Fraud Laporan Keuangan

Penelitian ini juga melakukan pengujian apakah ketiga variabel pressure factor berpengaruh positif signifikan terhadap fraud laporan keuangan. Hasil pengujian regresi berganda menggunakan uji $\mathrm{F}$ dapat dilihat pada tabel di bawah ini.

Tabel 5 Regresi Berganda menggunakan Uji F

\begin{tabular}{|l|r|r|r|r|r|}
\hline & \multicolumn{1}{|c|}{ ANOVA $^{\mathbf{a}}$} \\
Model & Squares & df & $\begin{array}{c}\text { Mean } \\
\text { Square }\end{array}$ & \multicolumn{1}{c|}{ F } & Sig. \\
\hline Regression & .203 & 3 & .068 & .53 & $.659^{\mathrm{b}}$ \\
& 13.387 & 106 & .126 & & \\
Residual & 13.589 & 109 & & & \\
Total &
\end{tabular}

a. Dependent Variable: Fscore (Y)

b. Predictors: (Constant), Leverage $\left(\mathrm{X}_{1 \mathrm{c}}\right)$, $\mathrm{ROA}\left(\mathrm{X}_{1 \mathrm{a}}\right)$, Achange $\left(\mathrm{X}_{1 \mathrm{~b}}\right)$

Sumber: Data diolah, 2021 
Berdasarkan tabel di atas, ketika dilakukan pengujian secara simultan, ditemukan hasil bahwa tidak terdapat pengaruh yang signifikan antara pressure factor terhadap fraud laporan keuangan. Hal ini terlihat dari nilai signifikansi yaitu sebesar 0.659 (diatas 0.05). Tidak adanya pengaruh yang signifikan antara pressure factor terhadap fraud laporan keuangan dapat disebabkan karena objek penelitian yang digunakan dalam penelitian ini ialah perusahaanperusahaan yang memiliki kondisi keuangan stabil, pertumbuhan perusahaan yang menjanjikan dan juga memiliki nilai transaski yang besar di bursa. Hal ini mengakibatkan manajemen tidak akan berniat untuk memanipulasi laporan keuangan karena nantinya akan berdampak pada citra perusahaan di mata investor. Selain itu, perusahaan yang stabil cenderung memiliki sistem pengendalian yang baik untuk medeteksi kecurangan yang terjadi di perusahaan, termasuk kecurangan dalam laporan keuangan.

\section{PENGUJIAN HIPOTESIS}

Tabel 5 Uji Regresi Berganda menggunakan Uji T

\begin{tabular}{|c|c|c|c|c|c|}
\hline \multirow[b]{3}{*}{ Model } & \multicolumn{3}{|c|}{ Coefficients $^{\mathrm{a}}$} & \multirow[b]{3}{*}{$\mathrm{t}$} & \multirow[b]{3}{*}{ Sig. } \\
\hline & \multicolumn{2}{|c|}{$\begin{array}{c}\text { Unstandardized } \\
\text { Coefficients }\end{array}$} & \multirow{2}{*}{$\begin{array}{c}\text { Standardized } \\
\text { Coefficients } \\
\text { Beta }\end{array}$} & & \\
\hline & B & $\begin{array}{l}\text { Std. } \\
\text { Error }\end{array}$ & & & \\
\hline 1 (Constant) & .063 & .052 & & 1.195 & .235 \\
\hline ROA (X1a) & .010 & .332 & .003 & .031 & .975 \\
\hline $\begin{array}{l}\text { Achange } \\
\text { (X1b) }\end{array}$ & .570 & .270 & .193 & 2.109 & .037 \\
\hline $\begin{array}{l}\text { Leverage } \\
\text { (X1c) }\end{array}$ & -.020 & .035 & -.052 & -.569 & .570 \\
\hline RR (X2) & 2.051 & .413 & -.452 & -4.965 & .000 \\
\hline CiA (X3) & -.038 & .098 & -.035 & -.390 & .697 \\
\hline
\end{tabular}

a. Dependent Variable: Fscore (Y)

Sumber: Data diolah, 2021

Tabel uji regresi berganda menggunakan uji

$\mathrm{T}$ digunakan untuk menjawab pengujian hipotesis yang diajukan.
Financial Target as Pressure Factor pada Fraud Laporan Keuangan

Financial Target yang diukur menggunakan rasio ROA memiliki nilai koefisien sebesar 
0.010 dengan nilai $\mathrm{t}$ sebesar 0.031 dan signifikansi sebesar 0.975. Hal ini menunjukkan bahwa financial target tidak dapat digunakan untuk mendeteksi adanya fraud laporan keuangan. Ketidak kemampuan ROA dalam mendeteksi fraud laporan keuangan dapat dikarenakan manajemen merasa bahwa ROA hanya digunakan untuk melihat kemampuan perusahaan menghasilkan profit dalam jangka pendek. Investor sudah tidak banyak menggunakan informasi yang terkandung dalam ROA. Umumnya, apabila profit perusahaan dalam jangka pendek relatif stabil, maka manajemen akan berusaha agar profit yang dihasilkan di tahun mendatang juga baik, sehingga manajemen tidak akan berpikir untuk melakukan kecurangan laporan keuangan dalam hal manipulasi laba (Nindhita A. Haqq \& Budiwitjaksono, 2019). Hasil penelitian ini sesuai dengan penelitan Apriliana, S. \& Agustina, L. (2017) dimana tidak terdapat pengaruh yang signifikan antara financial target yang diproksikan dengan ROA terhadap fraud laporan keuangan.Hal ini bisa dikarenakan objek penelitian yang terdiri dari perusahaan-perusahaan besar dimana tentunya telah memiliki perkembangan kualitas operasional yang baik dan ditunjang dengan SDM yang mumpuni sehingga target
ROA juga dapat tercapai sehingga tidak memungkinkan adanya kecurangan laporan keuangan untuk manipulasi laba.

\section{Financial Stability as Pressure Factor} pada Fraud Laporan Keuangan

Financial stability yang diukur menggunakan rasio perubahaan aset memiliki nilai koefisien sebesar 0.570 dengan nilai t sebesar 2.109 dan signifikansi di bawah 0.05. Ini berarti bahwa financial stability berpengaruh positif signifikan terhadap fraud laporan keuangan.Sehingga hipotesa kedua diterima dimana rasio perubahan aset dapat digunakan untuk mendeteksi adanya kecurangan pada laporan keuangan. Adanya hubungan yang positif antara financial stability dengan fraud laporan keuangan disebabkan karena manajemen melakukan berbagai tindakan agar perusahaan selalu dalam kondisi keuangan yang stabil.Semakin besar rasio perubahan aset, maka semakin tinggi manajemen melakukan kecurangan laporan keuangan. Hal ini agar pandangan investor atau pihak luar selalu positif terhadap perusahaan dan reputasi perusahaan tetap baik di mata masyarakat. Hasil ini sesuai dengan penelitian yang dilakukan oleh Apriliana, S. \& Agustina, L. (2017). 
External Pressure as Pressure Factor pada Fraud Laporan Keuangan

Tekanan luar yang diukur dengan rasio leverage menunjukkan nilai koefisien sebesar -0.020 dimana nilai t sebesar -0.569 dan signifikansi yaitu 0.570 . Hasil ini berarti bahwa hipotesa ditolak dimana tekanan eksternal tidak dapat mendeteksi adanya kecurangan laporan keuangan. Hal ini dikarenakan mayoritas perusahaan dalam mendapatkan pendanaannya ialah melalui hutang dan mereka tentunya tidak berkeinginan untuk melakukan kecurangan untuk menunjukkan kinerja yang baik kepada para kreditor.

Nature of Industry as Opportunity Factor pada Fraud Laporan Keuangan

Nature of industry diukur dengan rasio pengumpulan piutang menunjukkan nilai koefisien -2.051dengan nilai t sebesar -4.965 dan signifikasi di bawah 5 persen yaitu 0.000. Hasil ini menunjukkan bahwa hipotesa ditolak.Nature of industry berpengaruh signifikan negatif terhadap kecurangan laporan keuangan. Hal ini berarti rasio perputaran piutang yang rendah memiliki potensi terjadinya fraud laporan keuangan.

\section{Change in Auditor as Rationalization} Factor pada Fraud Laporan Keuangan

Perubahaan auditor memiliki koefisien sebesar -0.038 dengan nilai t sebesar -0.390 dan tingkat signifikansi di atas 0.05 , yaitu 0.697. Hal ini berarti adanya perubahaan auditor belum dapat mendeteksi adanya kecurangan dalam laporan keuangan. Perusahaan tidak perlu melakukan perubahaan auditor karena telah merasa yakin akan kemampuan auditor yang sebelumnya dan puas akan jasa yang telah mereka berikan. Aturan baru yang dikeluarkan melalui PP Nomor 20/2015 Pasal 11 ayat (1) tentang Praktik Akuntan Publik membatasi pemberian jasa audit atas informasi laporan keuangan oleh seorang Akuntan Publik paling lama untuk 5 (lima) tahun buku berturut-turut. Hal ini dapat menjadi penyebab penelitian ini kurang bisa merepresentasikan adanya perubahan auditor karena jangkauan penelitian terbatas pada 2016 - 2020 yaitu 5 (lima) tahun buku saja. 


\section{SIMPULAN}

Pengujian dengan analisis proksi fraud triangle telah dilakukan dengan hasil bahwa secara simultan financial target, financial stability, external pressure, nature of industry, dan change in auditor memiliki pengaruh signifikan positif terhadap fraud pada laporan keuangan. Adapun dengan pengujian hipotesis diketahui bahwa $\mathrm{H} 1 \mathrm{~b}$ terdukung yang berarti bahwa Pressure Factor dengan proksi Financial Stability berpengaruh positif pada adanya potensi fraud pada laporan keuangan. Auditor dalam mengaudit laporan keuangan perlu memperhatikan faktor tekanan dalam proksi stabilitas keuangan. Namun, hasil uji secara simultan terhadap proksi-proksi faktor pressure (tekanan) yaitu financial target, financial stability, dan external pressuretidak memiliki pengaruh signifikan positif. Adapun dari hasil pengujian secara parsial atas masing-masing variabel menyatakan bahwa hipotesis lainnya tidak terdukung. Diketahui bahwa financial target, external pressure, nature of industry, dan change in auditor tidak memiliki pengaruh signifikan positif terhadap adanya potensi fraud pada laporan keuangan. 


\section{DAFTAR PUSTAKA}

Abdullahi, R., \& Noorhayati, M. (2015)

.Fraud Triangle Theory and Fraud Diamond Theory. Understanding the Convergent and Divergent for Future Research. International Journal of Academic Reserach in Accounting, Finance and Management Sciences. , $38-45$.

ACFE. (2014). Report to the Nation. ACFE. AICPA. (2002). SAS No. 99, Consideration of Fraud in a Financial Statement Audit. New York: AICPA.

Albrecht, W., Albrecht, C., \& Albrecht, C. (2011). Fraud Examination (4th ed.). Mason, Ohio, USA: Cengage Learning.

Bastomi, J. (2018). 'Mendeteksi FaktorFaktor Yang Mempengaruhi Financial State-ment Fraud Dalam Perspektif Fraud Triangle. Jurnal Akuntansi Indonesia , 106-118.

Bawekes, H. F. (2018). Pengujian Teori Fraud Pentagon Terhadap Fraudulent Financial Reporting. Jurnal Akuntansi dan Keuangan Daerah, 114-134.

Dechow, P. M. (2011). Predicting material accounting misstatements. Contemporary accounting research, 17-82.

Kennedy, P., \& Siregar, S. (2017). Fraud Actors in Indonesia According to Fraud Indonesia Survey. Dalam Buletin Ekonomi FEUKI (hal. Vol. 21, No. 2).

Kurnia, A. \&. (2017). Analisis Fraud Pentagon Dalam Mendeteksi Kecurangan Laporan Keuangan dengan Menggunakan Fraud Score Model. Simposium Nasional Akuntansi XX, 1-30.
Manurung, T. H., \& Andhika Ligar, H. (2015). Analysis of Factors that Influence Financial Statement Fraud in The Perspective Fraud Diamond: Empirical Study on Banking Companies Listed on The Indonesia Stock Exchange Year 2012 to 2014. International Conference on Accounting Studies (ICAS). Johor.

Nindhita A. Haqq, A. P., \& Budiwitjaksono, G. S. (2019). Fraud Pentagon for Detecting Financial Statement Fraud. Journal of Economics, Business, and Accountancy Ventura , 319-332 .

Noble, M. R. (2019). Fraud diamond analysis in detecting financial statement fraud. The Indonesian Accounting Review, 121-132.

Nurbaiti, Z. \&. (2017). Analisis Pengaruh Fraud Diamond Dalam Mendeteksi Tingkat Accounting Irregularities. Jurnal Akuntansi Indonesia , 167184.

Ravisankar, P. R. (2011). Detection of financial statement fraud and feature selection using data mining techniques. Journal Decision Support Systems , 491-500.

Rezaee, Z. (2002). Financial Statement Fraud: Prevention and Detection. New York: John Wiley \& Sons, Inc.

Skousen, C. J. (2009). Detecting and predicting financial statement fraud: The effectiveness of the fraud triangle and SAS No. 99. Advances in Financial Economics , 53-81.

Wahyuni, W. \&. (2017). Fraud triangle sebagai pendeteksi kecurangan laporan keuangan. Jurnal Akuntansi, 47-61. 
Wilopo, R. (2014). Etika Profesi Akuntan: Kasus-Kasus di Indonesia (Edisi Kedua). Surabaya: STIE Perbanas Press.

Wolfe, D. T., \& Hermanson, D. R. (2004).
The Fraud Diamond: Considering The Four Elements of Fraud. The CPA Journal .

Yesiariani, M., \& Rahayu, I. (2017). Deteksi financial statement fraud: Pengujian dengan fraud diamond. Jurnal Akuntansi \& Auditing Indonesia , 4950 . 